\section{Angiographic computed tomography and computed tomographic angiography techniques: actual interventional and diagnostic possibilities of their use in patients with cerebral aneurysms}

\author{
Mario Carvi y Nievas \\ Department of Neurosurgery, Städtische \\ Kliniken Frankfurt am Main- Höchst, \\ Germany
}

\section{Abstract}

Since the introduction of radiological examination techniques, such as an angiographic computed tomography (ACT) and a computed tomographic angiography (CTA), the diagnosis and treatment planning for cerebral aneurysms became quicker and safer. Unfortunately, the state of development of these techniques, and their possible indications and benefits are still today restricted to specialized centers. The objective of this update was to analyze the current scientific evidence about their actual interventional and diagnostic use and identify the individual advantages of each through a literature review and personal experience-based data.

\section{Introduction}

Aneurysms of the intracranial vessels are relatively common, with a reported prevalence of $3-6 \%$ in the general population, predominantly in women. ${ }^{1}$ These aneurysms may rupture, causing subarachnoid hemorrhage. A subarachnoid hemorrhage is a neurological emergency characterized by the extravasation of blood into the spaces covering the central nervous system that are filled with cerebrospinal fluid. ${ }^{2}$

This disorder is also associated with a substantial burden on health care resources. The average case fatality rate for subarachnoid hemorrhage is $51 \%$, with approximately one third of survivors needing lifelong care. ${ }^{3}$ Most deaths occur within two weeks after the ictus, with $10 \%$ occurring before the patient receives medical attention and 25\% within 24 hours after the event. ${ }^{4}$

Due to the high mortality rate among patients with this condition, prompt localization of the aneurysm is critical for determining the appropriate neurosurgical or endovascular intervention. This can be extremely important for patients in poor condition with increased intracranial pressure. ${ }^{5,6}$ Digital subtraction angiography (DSA) is currently considered the imaging modality of choice for the evaluation of suspected aneurysms. DSA is an invasive test, however, and data from studies of patients who had subarachnoid hemorrhage or cerebral aneurysms and who underwent cerebral DSA indicate a $0.07 \%$ risk of permanent neurological complications. ${ }^{7,8}$

Taking into account all these data, the employment of additional techniques can be justified if they allow a reduction of possible complications, the acceleration of the diagnostic process or improve the interventional possibilities.

Since magnetic resonance angiography can be technically challenging to perform in the acutely ill patient, this update will be focused on other alternative or complementary angiographic examinations techniques used on patient admission.

\section{Actual interventional possibilities}

Several aneurysms and particularly large aneurysms may demonstrate unclear relationships to nearby structures and the parent vessel in DSA and magnetic resonance angiographic scans, which limits the usefulness of these methods for treatment planning. ${ }^{9}$ In the last four years, a new novel technique for obtaining cranial CT-like images using a biplane angiographic system has been developed. Angiographic computed tomography (ACT) is a new technique that provides crosssectional CT-like images based on rotational radiography performed with a rotating $\mathrm{C}$-armmounted flat-panel detector. This commercially available system combines a flat-detector biplane angiographic system (Axiom Artis dBA; Siemens Medical Solutions, Erlangen, German), with rotational radiography, as well as a new commercially available software (Dyna-CT). Siemens Medical Solutions introduced Dyna-CT for the first time in Europe at the European Congress of Radiology in March, 2005. This new application enables users of angiographic C-arm systems to create soft tissue images based on the principles of CT.

ACT allows the clear visualization of stents in both intracranial and extracranial arteries and is an even superior technique to conventional digital subtraction angiography and digital radiography in visualizing both the stent struts and their relationships with the arterial walls and aneurysmal lumen. Image post-processing corrects scattered radiation, beam hardening, and ring artefacts on a workstation. The display of imaged stents can be obtained by using multiplanar reconstructions. ${ }^{10}$ ACT allows determination of the correct stent position, which may be very helpful in complex stent-assisted aneurysm coiling procedures.
Correspondence: Mario Nazareno Carvi y Nievas, Oberarzt der Neurochirurgischen Klinik Städtische Kliniken Frankfurt am Main-Höchst 65929 Gotenstraße 6-8, FFM-Höchst, Germany E-mail: mcnievas@t-online.de

Key words: computed tomography, cerebral aneurysm.

Received for publication: 25 September 2009.

Revision received: 20 January 2010.

Accepted for publication: 15 February 2010.

This work is licensed under a Creative Commons Attribution 3.0 License (by-nc 3.0).

(C) Copyright M.N. Carvi y Nievas, 2010

Licensee PAGEPress, Italy

Neurology International 2010; 2:e7

doi:10.4081/ni.2010.e7

The relationship between arterial wall and stent struts is well visualized even with diluted contrast medium. In cases with aneurysms larger than $10 \mathrm{~mm}$ in diameter, beam hardening artifacts caused by the endoaneurysmal coil package can impair the visibility of the stent. ${ }^{11,12}$

In particular, the early recognition of any complication during endovascular procedures, whether these are followed or not by a neurosurgical intervention, has been demonstrated to be critical in improving the outcome of patients with aneurysmatic subarachnoid hemorrhage. ${ }^{13,14}$ In such cases, the prompt recognition of a developing intracranial mass effect caused by a hematoma, helps to optimize patient management. The results from Struffert et al. indicate that a flat-detector computed tomography is a helpful tool in the daily emergency management of ICH patients. The accuracy of this device for the detection of intracerebral hemorrhage was found to be nearly as reliable as that obtained by using multislice CTs. ${ }^{15}$

As a matter of fact, in anesthetized patients, significant ICP changes may become apparent only by elevations in systemic arterial blood pressure or signs of oculomotor nerve compression. In such patients, mobilization and transportation to a CT scanner cause significant loss of time and also compromise patient care during transportation. Therefore, not only the early development of intracranial bleedings, but also the progression of an acute hydrozephalus during the radiological procedure can be detected faster with ACT.

This technology can be also added to the surgical armamentarium in the operating theatre, not only because it allows the simultaneous visualization from blood vessels and surrounding parenchyma structures, but also because this produces real time images of the involved surgical fields. These easily obtained real time images will even probably mean that 
the use of other image guided devices such as a navigator becomes unnecessary. Intraoperatively obtained real time images are more useful for operator's decision making than pre-operatively loaded pictures. In this way, the operators are able to confirm not only the aneurysm occlusion and the patency of the vessels involved by the procedure, as well as the development of possible extravascular complications, but also the positioning from other soft tissue surgically implanted materials. The advantages of its use should be further examined, analyzing the accuracy of this new equipment for detecting some residual intracranial tumors as well as the positioning from some other implanted devices during complexes spinal surgeries.

Limitations of this technology are motion and beam-hardening artefacts that may mask small hematomas located in the posterior fossa or the skull base.

\section{Improved diagnostic and post- interventional controls}

In pre-selected difficult cases, intraoperative DSA angiography provides a high percentage of visualized angiographic abnormalities as well as an increased impact on corrective treatment. ${ }^{16}$ Nevertheless, in several hospitals today, a multislice computed tomographic angiography (CTA) is the preferred investigation for underlying causes of spontaneous subarachnoid hemorrhage because of its speed, tolerability, convenience, and the ability to provide three dimensional reconstructions..$^{17,18}$ The sensitivity of the procedure for identifying aneurysms greater than $3 \mathrm{~mm}$ diameter is about $96 \%$ but poorer for smaller aneurysms. ${ }^{19,20}$

The clinical usefulness of CTA scanning in cerebral aneurysms has been reported by several authors in the last 15 years. ${ }^{21-29}$ As a matter of fact, some authors have detected some peripherally located aneurysms of the posterior fossa only with CTA scanning. ${ }^{28,30}$ In DSA scans, the presence of vasospasm, the length and tortuosity of the parent arteries and the arterial cross-flow pattern within communicating arterial segments probably reduce aneurysm filling. Particularly in regions of vascular cross-flow, DSA and CTA scanning can be successfully combined, as demonstrated for anterior communicating artery aneurysms and aneurysms in the posterior circulation. ${ }^{21,31}$ In a previous study, we detected only 16 of the 25 posterior fosse ruptured aneurysms (64\%) on the first DSA scans and, even with repeated examinations, 6 aneurysms were not clearly identified with this technique. CTA scanning revealed the ruptured aneurysms in 25 cases, and demonstrated increased vascular filling and improved optical definition of the aneurysms, compared with DSA scanning in 12 cases (48\%). The information obtained from the CTA scans allowed the selection of 5 patients for endovascular treatment and facilitated the surgical procedures in 5 cases. ${ }^{21}$

Villablanca et al. reported that CTA scanning can provide complete aneurysm quantitation and characterization of both large and small aneurysms giving the incorrect impression that the use of DSA assessments should be reduced in the future. ${ }^{32}$ However, DSA scanning should be the initial method of evaluation for aneurysms since several anatomical vascular variations, small perforators, collateral circulation and flow dynamics are not well enough represented in CTA studies. In contrast, peripherally located aneurysms of the posterior circulation, which often exhibit reduced filling flow, and basilar artery aneurysms, which can be masked by cross-flow phenomena, are often overlooked on the first angiograms.

Lourenco et al. reported that 16-detector CTA did not improve detection of non-traumatic subarachnoid hemorrhage when compared with studies using single-detector $\mathrm{CT}^{33}$ However, in another recent study, the sensitivities of 16-slice CT angiography for aneurysms smaller than $5 \mathrm{~mm}$, between 5 and $10 \mathrm{~mm}$, and larger than $10 \mathrm{~mm}$ were $94.8,100$, and $100 \%$, respectively, on a per-aneurysm basis. ${ }^{34}$ Multidetector row CT (MDCT) scanners provided today increased spatial resolution and decreased scanning time, which increased the sensitivity of the technique in depicting small aneurysms. ${ }^{7}$ A recent review of the literature that compared 16-slice or 64-slice MDCT with catheter-based coronary angiography for the detection of coronary artery disease in nonrevascularized, post-stent and post-coronary artery bypass graft patients showed several improvements in spatial and temporal resolution with 64-slice technology. ${ }^{35}$ This improved accuracy and safety of MDCT may reduce future needs for different catheter-based angiography procedures.

On the other hand, experiences with this technique have shown how observer findings can differ. ${ }^{17}$ Particularly in the evaluation of patients with intracranial aneurysms who had undergone clip occlusion, the positive predictive value from multislice CTA on a per-patient basis is $86 \%$, for aneurysms at the clip site $83 \%$, and for aneurysms at different locations $91 \% .{ }^{36}$ On the other hand, cobalt clips produce much more artifact on CT scans than titanium clips making image evaluation difficult.

Finally, the combination of three-dimensional CTA and two-dimensional CT images may today help to improve the surgical outcome by indicating aneurysmal rupture points, leading to the prevention of rupture as reported by Wada et l $^{37}$

More recently, the employment of fourdimensional CT angiography also gives additional valuable information determining aneurysmal wall dynamics, such as the motions of the aneurysm-wall blebs..$^{38}$ Fourdimensional CT angiography is a novel technology that includes the dimension of time, which is repeated within a cardiac cycle. Fourdimensional CT angiography entails multislice computed tomography with a retrospective electrocardiography-gated reconstruction algorithm. The system uses high-resolution threedimensional imaging with temporal resolution in a beating heart to deliver clinically useful images of cerebral arteries. Visualization of a pulsating aneurysm in a gated acquisition will allow physicians to obtain novel and highly useful information regarding individual aneurysm features, such as dome pulsations, blebs and perhaps to predict their future hemodynamic behavior and chances of rupture.

\section{References}

1. Wardlaw JM, White PM. The detection and management of unruptured intracranial aneurysms. Brain 2000;123:205-21.

2. Suarez J, Tarr R, Selman W. Aneurysmal Subarachnoid Hemorrhage. N Engl J Med 2006;354:387-96.

3. Hop JW, Rinkel GJ, Algra A, van Gijn J. Case-fatality rates and functional outcome after subarachnoid hemorrhage: a systematic review. Stroke 1997;28:660-4.

4. Broderick JP, Brott TG, Duldner JE, et al. Initial and recurrent bleeding are the major causes of death following subarachnoid hemorrhage. Stroke 1994;25:1342-7.

5. Carvi y Nievas MN. Poor-grade subarachnoid hemorrhage patients: The use of nimodipine and other optional treatments. Neurol Res 1999;21:649-52.

6. Carvi y Nievas M, Hatingen Joerg. Interdisciplinary treatment selection in acute admitted SAH-patients. Neurol Res 2009;31:582-92.

7. Jayaraman M, Mayo-Smith W, Tung G, et al. Detection of intracranial aneurysms: multi-detector row CT angiography compared with DSA. Radiology 2004; 230:510-8

8. Cloft HJ, Joseph GJ, Dion JE. Risk of cerebral angiography in patients with subarachnoid hemorrhage, cerebral aneurysm, and arteriovenous malformation: a meta-analysis. Stroke 1999;30:31720.

9. Harbaugh RE, Schlusselberg DS, Jeffery R, et al. Three-dimensional computed tomographic angiography in the preoperative evaluation of cerebrovascular lesions. Neurosurgery 1995;36:320-6.

10. Benndorf G, Strother CM, Claus B, et al. Angiographic CT in cerebrovascular stenting. AJNR 2005;26:1813-8.

11. Richter G, Engelhorn T, Struffert T, et al. Flat panel detector angiographic CT for 
stent-assisted coil embolization of broadbased cerebral aneurysms. AJNR 2007; 28:1902-8.

12. Benndorf G, Claus B, Strother CM, et al. Increased cell opening and prolapse of struts of a neuroform stent in curved vasculature: value of angiographic computed tomography: technical case report. Neurosurgery 2006;58:0NS-E380

13. Carvi y Nievas MN, Haas E, Höllerhage HG. Severe intracranial bleedings during endovascular procedures. Outcome of surgically treated patients. Neurol Res 2007; 29:81-90.

14. Heran NS, Song JK, Namba K, Smith W, Niimi Y, Berenstein A. The utility of DynaCT in neuroendovascular procedures. AJNR 2006;27:330-2

15. Struffert T, Richter G, Engelhorn T, et al. Visualisation of intracerebral haemorrhage with flat-detector CT compared to multislice CT: results in 44 cases. Eur Radiol 2009;19:619-25.

16. Carvi y Nievas MN. Assessment of intracranial aneurysm clipping-efficacy. Analysis of the employed methodology in relationship to the case difficulty. Neurol Res 2007;29:506-16.

17. Pedersen HK, Bakke SJ, Hald JK, et al. CTA in patients with acute subarachnoid haemorrhage: a comparative study with selective, digital angiography and blinded, independent review. Acta Radiol 2001;42: 43-9.

18. Al-Shahi R, White P, Davenport R, Lindsay K. Subarachnoid haemorrhage. BMJ 2006; 333:235-40.

19. White PM, Wardlaw JM, Easton V. Can noninvasive imaging accurately depict intracranial aneurysms? A systematic review. Radiology 2000;217:361-70.

20. Van Gelder JM. Computed tomographic angiography for detecting cerebral aneurysms: implications of aneurysm size distribution for the sensitivity, specificity, and likelihood ratios. Neurosurgery 2003; 53:597-605.

21. Carvi y Nievas MN, Haas E, Höllerhage HG, Drahten C. Complementary use of computed tomographic angiography in treatment planning for posterior fossa sub- arachnoid hemorrhage. Neurosurgery 2002;50:1283-9.

22. Alberico RA, Patel M, Casey S, et al. Evaluation of the circle of Willis with three-dimensional CT angiography in patients with suspected intracranial aneurysm. AJNR 1995;16:1571-8.

23. Korogi Y, Takahashi M, Katada K, et al. Intracranial aneurysms: Detection with three-dimensional CT angiography with volume rendering. Comparison with conventional angiographic and surgical findings. Radiology 1999;211:497-506.

24. Le Roux PD, Dailey AT, Newell DW, et al. Emergent aneurysm clipping without angiography in the moribund patient with intracerebral hemorrhage: the use of infusion computed tomography scan. Neurosurgery 1993;33:189-97.

25. Nakajima Y, Yoshimine T, Yoshida H, et al. Computerized tomography angiography of ruptured cerebral aneurysm: factors affecting time to maximum contrast concentration. J Neurosurg 1998;88:663-9.

26. Ochi RP, Vieco PT, Gross CE. CT angiography of cerebral vasospasm with conventional angiographic comparison. AJNR 1997;18:265-9.

27. Takabatake Y, Uno E, Wakamatsu K,et al. The three-dimensional CT angiography findings of ruptured aneurysms hardly detectable by repeated cerebral angiography. No Shinkei Geka 2000;28:237-43.

28. Velthuis BK, van Leeuwen MS, Witkamp et al. Computerized tomography angiography in patients with subarachnoid hemorrhage: From aneurysm detection to treatment without conventional angiography. $\mathrm{J}$ Neurosurg 1999;91:761-7.

29. Zouaoui A, Sahel M, Marro B, et al. Threedimensional computed tomographic angiography in detection of cerebral aneurysms in acute subarachnoid hemorrhage. Neurosurgery 1997;41:125-30.

30. Iwanaga S, Shrier DA, Okawara SH, Numaguchi Y. Value of CT angiography in the evaluation of a peripheral inferior cerebellar artery aneurysm: case report. Clin Imaging 1999;23:77-80.

31. Hashimoto H, Iida J, Hironaka Y, et al. Use of spiral computerized tomography angiography in patients with subarachnoid hemorrhage in whom subtraction angiography did not reveal cerebral aneurysms. J Neurosurg 2000:92:278-83.

32. Villablanca JP, Martin N, Jahan R, et al. Volume rendered helical computerized tomography angiography in the detection and characterization of intracranial aneurysms. J Neurosurg 2000;93:254-64.

33. Lourenco AP, Mayo-Smith WW, Tubbs RJ, Sidman R. Does 16-detector computed tomography improve detection of nontraumatic subarachnoid hemorrhage in the emergency department? J Emerg Med 2008;34:319-20.

34. Chen W, Yang Y, Xing W, et al. Sixteen-row multislice computed tomography angiography in the diagnosis and characterization of intracranial aneurysms: comparison with conventional angiography and intraoperative findings. J Neurosurg 2008; 108:1184-91.

35. Kahn R, Rawal S, Eisenberg M. Transitioning from 16-slice to 64-slice multidetector computed tomography for the assessment of coronary artery disease: are we really making progress? Can J Cardiol. 2009;25:533-42.

36. van der Schaaf IC, Velthuis BK, Wermer MJ, et al. ASTRA Study Group. Multislice computed tomography angiography screening for new aneurysms in patients with previously clip-treated intracranial aneurysms: feasibility, positive predictive value, and interobserver agreement. $\mathrm{J}$ Neurosurg 2006;105:682-8.

37. Wada K, Arimoto H, Ohkawa H, et al. Usefulness of preoperative three-dimensional computed tomographic angiography with two-dimensional computed tomographic imaging for rupture point detection of middle cerebral artery aneurysms. Neurosurgery 2008;62:126-32

38. Ishida F, Ogawa H, Simizu T, et al. Visualizing the dynamics of cerebral aneurysms with four-dimensional computed tomographic angiography. Neurosurgery 2005;57:460-71. 